\title{
HUBUNGAN ANTARA BERAT PLASENTA IBU PREEKLAMPSIA DENGAN BERAT BAYI LAHIR DI RSUD dr. DORIS SYLVANUS KOTA PALANGKA RAYA TAHUN 2019
}

\author{
Lika Hanifah ${ }^{1}$, Sigit Nurfianto ${ }^{2}$, Ni Nyoman Sri Yuliani ${ }^{3}$ \\ ${ }^{l}$ Program Studi Pendidikan Dokter, Fakultas Kedokteran, Universitas Palangka Raya, Kota Palangka Raya, \\ Kalimantan Tengah, Indonesia \\ ${ }^{2}$ SMF Obstetri dan Ginekologi, RS dr. Doris Sylvanus, Kota Palangka Raya, Kalimantan Tengah, Indonesia \\ ${ }^{3}$ Departemen Gizi, Fakultas Kedokteran, Universitas Palangka Raya, Kota Palangka Raya, Kalimantan Tengah, \\ Indonesia \\ Email: Likahanfh@gmail.com
}

\begin{abstract}
ABSTRAK
Latar Belakang: Preeklampsia merupakan salah satu dari penyebab utama kematian ibu. Pada preeklampsia terjadi kelainan pembuluh darah plasenta ibu yang menyebabkan hipoksia kronis dan gangguan nutrisi janin sehingga mempengaruhi berat bayi yang akan dilahirkan. Tujuan: Penelitian ini dilakukan dengan tujuan untuk mengetahui hubungan antara berat plasenta ibu preeklampsia dengan berat bayi lahir di RSUD dr. Doris Sylvanus Palangka Raya Tahun 2019. Metode: Penelitian ini menggunakan desain penelitian observasional analitik dengan pendekatan cross-sectional. Sampel yang digunakan adalah sebanyak 35 sampel plasenta ibu preeklampsia yang melahirkan di RSUD dr. Doris Sylvanus Palangka Raya yang diambil dengan teknik consecutive sampling. Hasil: Hasil penelitian didapatkan rata-rata berat plasenta ibu preeklampsia adalah 499,4 gram $(\mathrm{SD}=146,685)$ dan rata-rata berat bayi lahir adalah 2.652,43 gram $(\mathrm{SD}=481,341)$. Berdasarkan dari analisis hasil uji korelasi Pearson berat plasenta ibu preeklampsia memiliki hubungan dengan berat bayi lahir di RSUD dr. Doris Sylvanus Kota Palangka Raya Tahun 2019 dengan $\mathrm{p}<0.001$ dan $r=0,679$. Kesimpulan: Berat plasenta pada ibu preeklampsia memiliki hubungan yang bermakna dengan berat bayi lahir di RSUD dr. Doris Sylvanus Kota Palangka Raya Tahun 2019 dengan tingkat hubungan yang kuat.
\end{abstract}

Kata kunci: Plasenta, berat plasenta, preeklampsia, berat bayi lahir

\begin{abstract}
Background: Preeclampsia is one of the leading causes of maternal death. In preeclampsia occurs abnormalities of maternal placental blood vessels that cause chronic hypoxia and fetal nutritional disorders that affect the weight of the baby born. Aim: The aim of this study was to find out the correlation between placental weight of preeclampsia mothers with the baby born weight at RSUD dr. Doris Sylvanus Palangka Raya City in 2019. Method: This study uses an analytic observational research design with a cross-sectional approach. The sample used was 35 placenta samples from preeclampsia mothers who gave birth at RSUD dr. Doris Sylvanus Palangka Raya taken by consecutive sampling technique. Result: The results showed that mean of placental weight in preeclampsia mothers was 499.4 grams $(\mathrm{SD}=146,685)$ an mean of baby born weight was 2,652.43 grams ( $\mathrm{SD}=481.341$ ). Based on the analysis of Pearson correlation test results of placental weight of preeclampsia mothers have a correlation with the weight of babies born at RSUD dr. Doris Sylvanus City of Palangka Raya in 2019 with p $<0,001$ and $r=0.679$. Conclusion: The weight of the placenta in preeclampsia mothers has a significant correlation with the weight of babies born at RSUD dr. Doris Sylvanus Palangkaraya City 2019 with the strong level of correlation.
\end{abstract}

Keywords: Placenta, Placenta weight, Preeclampsia, baby born weight 


\section{PENDAhuluan}

Angka kematian ibu (AKI) dan bayi merupakan salah satu indikator pembangunan dalam bidang kesehatan di seluruh dunia yang dapat menggambarkan kesejahteraan masyarakat di suatu negara termasuk di Indonesia. ${ }^{1}$ WHO memperkirakan pada tahun 2015, sekitar 303.000 orang perempuan meninggal saat kehamilan dan setelah melahirkan serta sekitar 2,7 juta bayi baru lahir meninggal di dunia. ${ }^{2}$ Data dari Kementerian Kesehatan Republik Indonesia (Kemenkes) tahun 2015 menunjukkan bahwa dari 100.000 kelahiran hidup di Indonesia, 305 di antaranya berakhir dengan kematian sang ibu. $^{3}$ Hasil Survei Demografi dan Kesehatan Indonesia (SDKI) tahun 2017 menunjukkan Angka Kematian Neonatal (AKN) sebesar 15 per 1.000 kelahiran hidup. ${ }^{4}$ Jumlah kasus kematian ibu hamil yang dilaporkan di Provinsi Kalimantan Tengah pada Tahun 2016 sebanyak 74 kasus. Angka ini menurun dibandingkan tahun $2015 .^{5}$

AKI adalah jumlah kematian ibu akibat dari proses kehamilan, melahirkan, dan setelah melairkan sedangkan angka kematian neonatal adalah jumlah kematian bayi per 1000 kelahiran hidup pada bayi kurang dari 4 minggu sedangkan kematian ibu menurut WHO adalah kematian selama kehamilan atau dalam periode 42 hari setelah berakhirnya kehamilan, akibat semua sebab yang terkait dengan atau diperberat oleh kehamilan atau penanganannya, tetapi bukan disebabkan oleh kecelakaan atau cedera. ${ }^{1,13}$ Kematian ibu akibat persalinan merupakan masalah yang bersifat multidimensional yang tidak hanya disebabkan oleh faktor kesehatan sang ibu semata seperti kekurangan gizi, anemia dan hipertensi, melainkan juga turut dipengaruhi oleh faktor eksternal seperti ketersediaan infrastruktur kesehatan yang memadai, serta kesadaran keluarga untuk meminta bantuan tenaga kesehatan dalam proses persalinan. ${ }^{6}$ Komplikasi utama yang menyebabkan hampir 75\% dari semua kematian ibu adalah perdarahan hebat, infeksi, hipertensi selama kehamilan (preeklampsia dan eklampsia), komplikasi dari persalinan aborsi yang tidak aman dan sisanya disebabkan oleh atau terkait dengan penyakit seperti malaria, dan AIDS selama kehamilan dengan penyebab utama kematian neonatal terkait erat dengan kualitas pelayanan persalinan dan penanganan berat bayi lahir yang kurang optimal segera setelah lahir dan beberapa hari pertama setelah lahir.

Preeklampsia/eklampsia selain merupakan salah satu penyebab kematian ibu, juga mempunyai kontribusi besar terhadap kematian janin dan BBL karena terkait dengan asfiksia dan prematuritas. ${ }^{1,7}$ Preeklampsia merupakan penyebab ke-2 kematian ibu di dunia setelah perdarahan. ${ }^{8}$ Pada preeklampsia/eklampsia terjadi penurunan perfusi utero plasenta, hipovolemia, vasospasme, dan kerusakan sel endotel pembuluh darah plasenta. ${ }^{9,11}$

Berdasarkan survei pendahuluan yang telah dilakukan diperoleh data pada tahun 2017 terdapat 241 kasus preeklampsia dan meningkat pada tahun 2018 sebanyak 260 kasus. Angka kejadian BBLR Kalimantan Tengah pada tahun 2017 sebanyak 797 kasus. Jumlah tersebut lebih tinggi dibandingkan dengan pada tahun 2016 sebanyak 645 kasus dan pada tahun 2015 sebanyak 556 kasus. Angka ini menunjukkan adanya peningkatan dari tahun ke tahun selama 3 tahun terakhir. Berdasarkan data yang diperoleh dari Rekam Medis di RSUD Dr. Doris Sylvanus Kota Palangka Raya ini, peneliti tertarik melakukan penelitian apakah terdapat hubungan antara berat plasenta bayi dengan ibu preeklampsia terhadap berat badan bayi lahir di RSUD Dr. Doris Sylvanus Kota Palangka Raya tahun 2019. ${ }^{12}$ Berdasarkan latar belakang yang telah diuraikan peneliti di atas, dapat dirumuskan masalah sebagai berikut, yaitu:Bagaimana berat plasenta bayi pada ibu preeklampsia di RSUD Dr. Doris Sylvanus 
Kota Palangka Raya tahun 2019, bagaimana berat badan bayi lahir pada ibu preeklampsia di RSUD Dr. Doris Sylvanus Kota Palangka Raya tahun 2019, dan apakah terdapat hubungan antara berat plasenta bayi dengan berat badan bayi lahir pada ibu preeklampsia di RSUD Dr. Doris Sylvanus Kota Palangka Raya tahun 2019. Secara umum penelitian ini bertujuan untuk mengetahui hubungan antara berst plasenta bayi dengan berat badan bayi labir pada ibu preeclampsia.

\section{METODE PENELITIAN}

Jenis penelitian ini merupakan penelitian non eksperimen (analitik observasional). Rancangan penelitian yang digunakan adalah dengan pendekatan Cross sectional yang dilakukan dengan menganalisis data sekunder dan rekam medis. Populasi dalam penelitian ini adalah seluruh plasenta ibu yang melahirkan dengan preeklampsia di RSUD Dr. Doris Sylvanus Kota Palangka Raya tahun 2019. Sampel penelitian ini adalah subjek yang memenuhi kriteria inklusi yang telah ditentukanoleh peneliti. Kriteria inklusi meliputi plasenta dari ibu dengan diagnosis preeklampsia yang melahirkan di RSUD Dr. Doris Sylvanus Kota Palangka Raya tahun 2019, ibu melahirkan dengan usia kehamilan aterm (37-42 minggu), janin tunggal, plasenta lahir utuh, plasenta lahir ditimbang $<1$ jam. Teknik pengambilan sampel adalah dengan teknik consecutive sampling. Sampel yang digunakan dalam penelitian ini berjumlah 35 orang. Jenis data yang dgunakan dalam penelitian ini adalah data primer dan data sekunder. Prosedur analisis data yang digunakan yaitu analisis univariat dan bivariate dengan menggunakan uji korelasi Pearson.

\section{HASIL DAN PEMBAHASAN}

Tabel 1. Tabel Distribusi Berat Plasenta Ibu Preeklampsia dan Berat Bayi Lahir di RSUD Dr. Doris Sylvanus Tahun 2019

\begin{tabular}{lllll}
\hline 1. & Berat Plasenta & 499,40 & 146,685 & 465 \\
& Ibu & & \\
& Preeklampsia & & & \\
2. & Berat Bayi & 2652,43 & 481,341 & 2700 \\
& Lahir & & & \\
\end{tabular}

Dari hasil analisis didapatkan rata-rata berat plasenta ibu preeklampsia sebesar 499,40 gr, median 465 gr dan standar deviasi 146,685 gr dengan berat plasenta ibu preeklampsia terrendah adalah 278 gr sedangkan tertinggi adalah $922 \mathrm{gr}$. Sementara itu pada berat bayi lahir didapatkan rata-rata sebesar 2.652,43 gr, median 2.700 gr dan standar deviasi 481,341 gr dengan berat bayi terkecil 1450 gr dan terbesar 4000 gr.

\section{Tabel 2. Hasil Analisis Korelasi Pearson}

\begin{tabular}{lll}
\hline & $\begin{array}{l}\text { Berat } \\
\text { Lahir }\end{array}$ \\
\hline Berat Plasenta Ibu & $\mathrm{r}=0,679$ \\
Preeklampsia & $\mathrm{p}<0,001$ \\
& $\mathrm{n}=35$ \\
\hline
\end{tabular}

\section{Uji Korelasi Pearson}

Dari tabel di atas dapat dilihat bahwa hasil analisis uji statistik menggunakan korelasi pearson didapatkan nilai koefisien korelasi Pearson (r) sebesar 0,679 dengan $\mathrm{p}$ value $<0,001$ yang menunjukkan bahwa terdapat hubungan signifikan antara berat plasenta $\mathrm{ibu}$ preeklampsia dengan berat bayi lahir. Secara statistik korelasi tersebut bernilai kuat karena lebih dari 0,6 dengan arah korelasi positif.

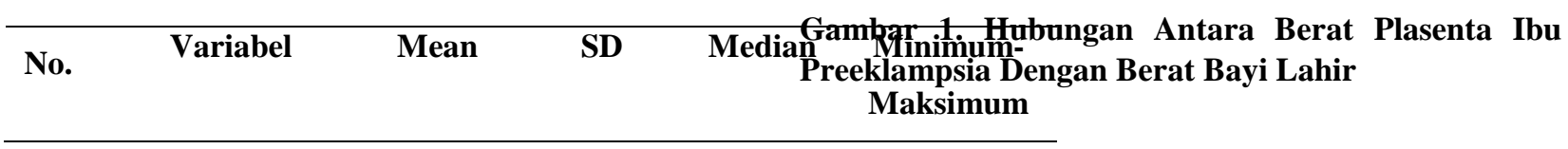




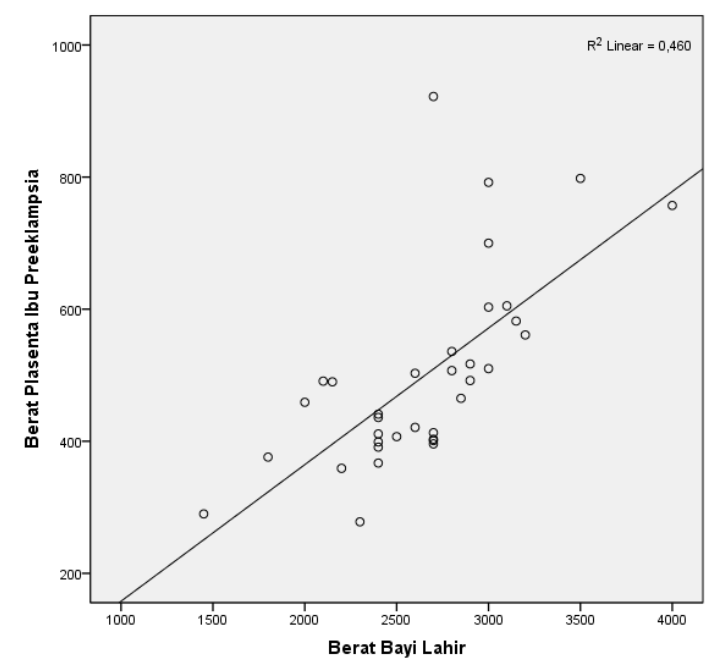

Dari bentuk grafik yang dihasilkan, maka grafik dari Scatter Diagram di atas menyatakan adanya hubungan positif (korelasi positif) yang artinya semakin rendah berat plasenta pada ibu preeklampsia maka semakin rendah berat bayi lahir.

\section{PEMBAHASAN}

Plasenta merupakan organ yang berasal dari lapisan trofoblas pada ovum yang dibuahi dan terhubung dengan sirkulasi ibu untuk melakukan fungsi yang belum dapat dilakukan janin di dalam intrauterin. ${ }^{43}$ Pada keadaan normal berat plasenta akan bertambah oleh adanya pertumbuhan vilus plasenta. Vilus-vilus ini yang berfungsi sebagai tempat pertukaran makanan, oksigen, dan zat sisa janin sehingga berat plasenta penting dalam menentukan berat bayi lahir. ${ }^{37,49}$

Sementara pada kehamilan dengan preeklampsia suplai uteroplasenta yang terganggu akan menyebabkan gangguan fungsi plasenta dalam menyalurkan bahan makanan dan nutrisi yang diperlukan bagi janin sehingga pasokan nutrisi yang dialirkan dari plasenta ke janin menjadi berkurang dan dapat mempengaruhi berat bayi lahir. Banyak peneliti berpendapat bahwa disfungsi endotel memainkan peranan penting dalam patogenesis preeklampsia. Penyebab dari disfungsi endotel adalah multifaktorial. Stress oksidatif, paparan sitokin inflamasi, dan hiperkolestrolemia merupakan beberapa penyebab disfungsi endotel. Akibat dari disfungsi endotel terjadi penurunan perfusi darah plasenta. Penurunan perfusi darah plasenta inilah yang mempengaruhi perkembangan plasenta sehingga mengakibatkan janin mengalami hipoksia. Keadaan hipoksia pada janin dapat menganggu pertumbuhan pertumbuhannya di dalam kandungan yang terlihat pada berat bayi lahir. ${ }^{50,51}$

Berdasarkan hasil uji statistik analisis korelasi Pearson dengan nilai $\mathrm{r}=0,679$ dan memiliki nilai signifikan $p=0.000$ dengan arah korelasi positif memberikan kesimpulan bahwa adanya hubungan yang signifikan antara berat plasenta ibu preeklampsia dengan berat bayi lahir di RSUD Dr Doris Sylvanus Kota Palangka Raya tahun 2019 sehingga dengan adanya hasil tersebut hipotesis semakin rendah berat plasenta ibu preeklampsia maka semakin rendah berat bayi lahir diterima. Hal ini sesuai dengan teori bahwa salah satu penentu utama berat bayi lahir adalah berat plasenta karena oksigen dan makanan didistribusikan melalui plasenta ibu ke janin. ${ }^{45}$

Teori lain menguatkan bahwa pada preeklampsia terjadi vasokonstriksi pembuluh darah dalam uterus yang menyebabkan resistensi perifer sehingga terjadi peningkatan tekanan darah. Vasokonstriksi pembuluh darah dalam uterus dapat mengakibatkan penurunan aliran darah sehingga suplai oksigen dan nutri ke janin berkurang. Ketika hal ini terjadi, dapat menyebabkan intrauterine growth retardation (IUGR) dan melahirkan bayi dengan berat lahir rendah. ${ }^{46,47}$ Keadaan lain juga diperjelas akibat kegagalan arteri spiralis di miometrium untuk dapat 
mempertahankan struktur mukoelastisitasnya, di samping itu juga terjadi arterosis akut pada arteri spiralis yang dapat menyebabkan lumen arteri bertambah kecil. Keadaan tersebut akan menyebabkan infark plasenta dan bisa mengakibatkan hipoksia janin hingga kematian janin. ${ }^{48}$ Teori tersebut juga didukung oleh penelitian James M dengan judul The Placenta in Preeclampsia di Universitas Pittsburgh Amerika yang mengatakan bahwa perubahan yang terjadi pada plasenta seseorang dengan preeklampsia berhubungan dengan iskemia plasenta. ${ }^{36}$

Menurut hasil penelitian Berit Dahlstrom dengan judul Placenta Weight in Pre-eclampsia dikatakan bahwa pada preeklampsia aterm, rata-rata $z$-score pada berat plasenta secara signifikan lebih tinggi dibandingkan dengan kehamilan tanpa preeklampsia (0,045 dibandingkan dengan 0,013, p < 0,05). Ratarata berat plasenta kasar adalah 672 gram pada kehamilan tanpa preeklampsia, 675 gram pada kehamilan aterm, dan 475 gram pada kehamilan dengan preeklampsia preterm. Hasil penelitiannya menunjukkan bahwa di dalam seluruh populasi berat bayi lahir dan berat plasenta memiliki hubungan dengan nilai $r=0,64$ dan nilai signifikan $p<0.00$ serta ia juga mengatakan bahwa berat plasenta yang rendah sangat besar hubungannya dengan preeklampsia preterm dan terdapat hubungan yang kuat antara berat plasenta yang rendah dengan berat bayi lahir rendah. ${ }^{30}$

\section{KESIMPULAN}

Berdasarkan hasil dan pembahasan penelitian yang diperoleh maka dapat disimpulkan sebagai berikut:

1. Rata-rata berat plasenta ibu preeklampsia yang melahirkan adalah sebesar 499,4 gram yang berada dalam batas normal berat plasenta.
2. Rata-rata berat bayi yang dilahirkan oleh ibu preeklampsia adalah sebesar 2652,43 gram yang berada dalam batas normal berat bayi lahir.

3. Terdapat hubungan yang kuat antara berat plasenta ibu preeklampsia dengan berat bayi lahir di RSUD dr. Doris Sylvanus Kota Palangka Raya tahun 2019 dengan $r=0,679$ dengan $p$ value $<0,001$. Dengan hasil $r$ positif maka semakin rendah berat plasenta ibu preeklampsia maka semakin rendah berat bayi lahir.

\section{DAFTAR PUSTAKA}

1. Endang L A. Kematian Maternal dan Neonatal di Indonesia. Rakernas Depkes FK UI. Jakarta. 2019. Diakses pada tanggal 18 Maret 2019 di http://www.depkes.go.id/resources/download/inf o-terkini/rakerkesnas 2019/SESI\%20I/Kelompok\%201/1-KematianMaternal-dan-Neonatal-di-Indonesia.pdf

2. WHO. Maternal Mortality. 2015 Diakses pada $\begin{array}{llll}\text { tanggal } & 29 & \text { Maret }\end{array}$ di http://www.who.int/mediacentre/factsheets/fs 348/en/

3. Badan Penelitian dan Pengembangan Kesehatan. Hasil Riset Kesehatan Dasar Kalimantan Tengah. 2013.

4. Kementerian Kesehatan RI. INFODATIN. Pusat Data dan Informasi Kementerian Kesehatan Situasi Kesehatan Ibu. 2015

5. Dinas Kesehatan Provinsi Kalimantan Tengah. Profil Kesehatan Provinsi Kalimantan Tengah. Palangkaraya: Dinkes Provinsi Kalimantan Tengah. 2016

6. Arief R. Kematian Ibu dan Upaya-Upaya Penanggulangannya. Perkumpulan Keluarga Berencana Indonesia. 2019. Diakses pada tanggal $18 \quad$ Maret 2019 di https://pkbi.or.id/kematian-ibu-dan-upayaupaya-penanggulangannya/

7. Saifuddin AB. Panduan Praktis Pelayanan Kesehatan Maternal dan Neonatal. Jakarta: EGC. 2009

8. Eny P. Hubungan Antara Umur Dan Status Gizi Ibu Berdasarkan Lingkar Lengan Atas Dengan 
Jenis BBLR. Jurnal Penelitian Kesehatan. 2016;7(1):1-2

9. National Institute for Health and Clinical Excellence (NICE). Hypertension in Pregnancy: The Management of Kingdom. National Institute for Health and Clinical Excellence. 2010

10. Rekam Medik RSUD Dr Doris Sylvanus Kota Palangka Raya Provinsi Kalimantan Tengah. 2018

11. Cunningham FG, Leveno KJ, Bloom SL, Hauth JC, Rouse DJ, Spong CY. Hipertensi dalam Kehamilan. Dalam Obstetri Williams. Edisi 23. Jakarta: EGC. 2014

12. Chung SH, Choi YS, Bae CW. Changes in the neonatal and infant mortality rate and the causes of death in Korea. Korean Journal of Pediatrics. 2014

13. Nuning S. Hipertensi Dalam Kehamilan, Ilmu Kebidanan Ed 4. Jakarta: Bina Pustaka Sarwono Prawirohardjo. 2010:53

14. Burton GJ, Wood AW, Jauniaux E, Kingdom JCP. Rheological and Physiological Consequences of Conversion of The Maternal Spiral Arteries For Uteroplacental Blood Flow During Human Pregnancy. 2009:473-482

15. Manuaba, et al. Ilmu Kebidanan, Penyakit Kandungan dan Keluarga Berencana Untuk Pendidikan Bidan Ed 2. Jakarta: EGC. 2010.

16. Laneloh, DC. Preeklampsia Berat dan Eklampsia: Tatalaksana Anestesia Perioperatif. Ed 1. Yogyakarta: Deepublish. 2018:4-5

17. Prawirohardjo, S. Ilmu Kebidanan. Jakarta: Bina Pustaka. 2010

18. Parker SE, Werler MM, Gissler M, Tikkanen M, Ananth CV. Placental Abruption and Subsequent Risk of Pre-eclampsia: A Population-Based Case-Control Study. Pediatric and Perinatal Epidemiologi. 2015;29(3): 211-9

19. Eastabrook G, Brown M, Sargent I. The origins and end-organ consequence of pre-eclampsia. Clinical Obstetrics and Gynaecology. 2011;25(4):435-447

20. Loftin RW, Habli M, Snyder CC, Cormier CM, Lewis DF, DeFranco EA. Late Preterm Birth. Reviews in Obstetrics and Gynecology. 2010;3(1): 10-19

21. Srinivas SK, Edlow G, Neff PM, Sammel MD, Andrela CM, Elovitz M. Rethinking IUGR in preeclampsia: dependent or independent of maternal hypertension. Journal of Perinatology : Official Journal of the California Perinatal Association. 2009;29(10): 680-4

22. Harmon Q, Huang L, Umbach D, Klungsoyr K, Engel S, Magnus P, et al. Risk of Fetal Death With Preeclampsia. HHS Public Access. 2012;73(4): 389-400.

23. Eroschenko VP. Atlas Histologi diFiore Dengan Korelasi Fungsional. Jakarta: EGC. 2015

24. Heffner LJ, Schust DJ. At a Glance Sistem Reproduksi Ed. 2. Penerbit Erlangga. 2005

25. Gant NF, Cunningham FG. Dasar-Dasar Ginekologi \& Obstetri. Jakarta: EGC. 2010

26. Manuaba IB, Chandranita IA, Fajar IB. Pengantar Kuliah Obstetri. Jakarta: EGC. 2012

27. Sherwood L. Fisiologi Manusia Dari Sel ke Sistem Ed 8. Jakarta: EGC. 2014

28. Purwaningsih W, Fatmawati S. Asuhan Keperawatan Maternitas. Yogyakarta: Nuha Medika. 2010

29. Ezeigwe CO, Okafor CI, Eleje GU, Udigwe Go. Placental Peripartum Pathologies in Women with Preeclampsia and Eclampsia. Fetomaternal Unit Department of Obstetrics and Gynecology. Nigeria. 2018

30. Berit D et al. Placenta Weight in Pre-Eclampsia. Faculty Division Akershus University Hospital, University of Oslo. Norway. 2008:610

31. Kosim MS, Yunanto A, Dewi R, Sarosa GI, Usman A. Buku Ajar Neonatologi. Badan Penerbit IDAI. 2014

32. Fatmawati, M., \& Windraswara, R. Faktor Risiko Paparan Pestisida Selama Kehamilan Terhadap Kejadian BBLR Pada Petani Sayur. Fakultas Ilmu Kesehatan Masyarakat Unnes. 2016;(4):306-315

33. Proverawati A, Ismawati C, S. BBLR : Berat Badan Lahir Rendah. Yogyakarta: Nuha Medika. 2010

34. Mukhlis, H. Hubungan Berat Plasenta dengan Berat Badan Bayi Lahir Di Kota Pariaman. FK Unand. 2013

35. Jebbink J, Wolters A, Fernando F. Molecular Genetics of Preeclampsia and HELLP Syndrome. 2012

36. Roberts JM, Escudero C. The Placenta in Preeclampsia. Department of Obstetrics and Gynecology. University of Pittsburgh. USA. 2012

37. Cunningham FG et al. Pertumbuhan dan Perkembangan Janin dalam: 
Hartono $\mathrm{H}$ et al (editor). Obstetri Williams. Ed ke-24. Vol 1. Jakarta: EGC. 2017:146

38. Dekker GA, Sibai BM. Ethiology and Pathogenesis of Preeclampsia. Current Concepts. Am J Obstetrics and Gynecology. 2010:13591998

39. Kim $\mathrm{K}$ et al. Nanoscale imaging of Morphological Changes of Umbilical Cord in Pre-eclampsia. 2012:1445

40. Myatt et al. Oxidative Stress in The Placenta. 2004:369

41. Eroschenko VP. Atlas Histologi diFiore Dengan Korelasi Fungsional. Jakarta: EGC. 2015

42. Kesha BR. Maternal Risk Factors For Abnormal Placental Growth: The National Collaborative Perinatal Project. US National Library of Medicine National Institutes of Health. 2008

43. Sofian A. Rustam Muchtar Sinopsis Obstetri. Jakarta: EGC. 2011

44. Soetjiningsih. Tumbuh Kembang Anak. Jakarta: EGC. 2014

45. Guyton AC, Hall JE. Kehamilan dan Laktasi. Dalam: Rachman LY dkk (editor). Buku Ajar Fisiologi Kedokteran. Edisi ke-11. Jakarta: EGC. 2008
46. Backes $\mathrm{CH}$, et al. Maternal Preeclampsia and Neonatal Outcomes. Journal of Pregnancy.

2011;1:7

47. Elmira. Hubungan Antara Usia Ibu, Gravida, dan Frekuensi ANC Dengan Kejadian Bayi Berat Bada Lahir Rendah Pada Pasien Preeklampsia Berat/Eklampsia di RSU Bhakti Yudha Depok Periode Januari 2006-Desember 2010. Universitas Pembangunan Nasional Veteran Jakarta. Jakarta. 2011.

48. Castro C. Hypertensive disorders of Pregnancy. In: Hacker \& Moore's Essensial of Obstetri and Gynecology 6th Ed. Elsivlersaunders: Philadelphia. 2015

49. Syahdrajat T. Panduan Penelitian Untuk Skripsi Kedokteran \& Kesehatan. Fakultas Kedokteran Universitas Indonesia. Jakarta. 2019

50. Evanov S, Durry M, Lintong P. Gambaran Histopatologi Plasenta Pada Kehamilan Dengan Preeklampsia. Departemen Patologi Anatomi Fakultas Kedokteran Universitas Sam Ratulangi Manado. Manado. 2013;1(2)

51. Sunarto, Suparji, Ayu AK. Hubungan Antara Hipertensi, Proteinuria ibu Preeklampsi Dengan Kejadian Asfiksia Neonatorum di RSU dr. Harjono S. Ponorogo. 2010;1(4) 